\title{
Assessing the Life Cycle of Existing Maritime Structures - Application to a Harbour Bridge in Porto Port
}

\author{
David D. Pereira, Vicente N. Moreira, Aires Camões, \\ and José C. Matos ${ }^{(凶)}$ \\ Department of Civil Engineering, Engineering School, University of Minho, \\ Campus de Azurém, 4800-058 Guimarães, Portugal \\ jmatos@civil.uminho.pt
}

\begin{abstract}
Since the construction industry is the one that bears most expenses, both in financial and environmental terms, it is of the upmost importance that these expenses originate a product with a long term exploitation, so as to mitigate them. Having this problem in consideration, in this paper the bridge located in the north of Portugal, near Porto, in the oil tanker terminal at the Leixões port was studied. This structure is located in one of the most aggressive environments for concrete structures, a maritime zone. The most accepted durability models in the country, related to deterioration induced by sea chlorides penetration, were then implemented. Thereby, it was possible to identify which model better reflects reality, since the structure in analysis is now at the end of its lifetime, after 50 years of service and shows advanced degradation due to chloride attack.

In the context of this work, the structure and the test methods relevant to the theme being studied were described by inspection reports and in situ test results, made available by the Douro and Viana do Castelo Port Authority. From this data it was possible to study the structure deterioration by introducing them into durability models. These models range from prescriptive to performance based approaches, being possible to identify, from the later ones, a deterministic model, based on the Model Code 2010, a semi-probabilistic based on the E465 specification from the Portuguese National Laboratory for Civil Engineering (LNEC) and two probabilistic models, based on the same standards, for which a computer code was developed during this work. Through these deterioration prediction tools, different project scenarios were established, originating a list of minimal concrete covers to ensure 100 years of lifetime to a structure built in the studied exposure zone.
\end{abstract}

Keywords: Maritime exposure · Life cycle analysis · Deterioration mechanism $\cdot$ Deterministic and probabilistic models $\cdot$ Performance assessment

\section{Introduction}

In most European Union countries approximately 50\% of the expenses in the construction industry are due to repairs, maintenance and rehabilitation of existing structures, expenses that will continue to grow in the future. The largest portion of these expenses are related to poor durability in concrete structures (Ferreira 2004). 
One of the main concerns for a design engineer when specifying concrete for an aggressive environment is verifying its intended lifetime. A lot of research on this matter has been done lately in order to describe durability and performance of concrete structures for long periods of time. In particular, in the development of new durability design procedures a probabilistic approach is generally recommended (Ferreira 2004).

Fick's second law is the base for durability models related to the effects of sea chloride diffusion in concrete. This take into account factors such as the diffusion coefficient, time, and temperature. An analysis of this nature can equally be applied for long term performance and durability control of new structures as well as to evaluate degradation of existing structures in a marine environment.

The objective of this paper was to collect information about the most accepted durability models, namely the E465 specification from LNEC (2007) and the fib Model Code 2010 (2010). Maritime structures such as the Leixões Harbour are an example of a type of structure where the improvement and validation of these models is essential, due to the aggressiveness of the environmental exposure, namely the chloride attack and due to its advanced degradation. Therefore, it will be possible to input real data in the lifetime prediction tools, with the purpose of determining the most suitable method for this structure.

\section{Concrete Degradation Mechanisms}

Deterioration is any adverse change of normal, mechanical, physical, and chemical properties either in the surface or in the body of concrete, generally due to the disintegration of its components (Masters and Brandt 1987). For concrete deterioration to occur it is necessary for the environmental aggressive agents to penetrate through gases or liquids existing in the pores and the reaction of these elements with the cement matrix or to exceed a critical concentration level. Aggressive agents, such as chlorides, weaken concrete, generating cracks and loss of binding capacity, therefore allowing further penetration of these agents and further deterioration.

\subsection{Chloride Diffusion}

Chlorides penetrate in maritime structure's concrete from the environment through sea water or through the presence of the ion in the cement paste due to contaminated aggregates and water. Of all the chloride transport processes in concrete, the most important one for this case study is diffusion.

Diffusion is the penetration of chlorides due to a concentration gradient and it is most severe in saturated environments, which allows the transport of this ion through the concrete's water filled pores. Chlorides act as catalysts to corrosion which is manifested when its concentration is high enough to destroy the rebar's passive layer. The chloride concentration that initiates steel corrosion is called critical chloride content. Chloride diffusion, from the concrete surface to the reinforcement bar zone can be described by Fick's second law. This law is the basis for the LNEC E465 (2007) and fib Model Code (2010) models, studied in this paper, respectively. The former one is given by expression 1 : 


$$
C(x, t)=C_{s} \times\left[1-\operatorname{erf}\left(\frac{x}{2 \sqrt{D t}}\right)\right]
$$

where $D$ is the chloride diffusion coefficient, $C(x, t)$ is the chloride concentration at depth $x$ and time $t, C s$ is the surface chloride concentration, erf is the error function and $x$ is the concrete cover depth. While the latter is described by expression 2 :

$$
C(x, t)=C_{0}+\left(C_{s, \Delta x}-C_{0}\right) \times\left[1-\operatorname{erf} \frac{c_{n o m}-\Delta x}{2 \times \sqrt{D_{a p p}(t) \times t}}\right]
$$

where $C_{0}$ is the initial chloride concentration in the concrete, $C_{s, \Delta x}$ is the chloride concentration at a depth of $\Delta x, c_{n o m}$ is the concrete cover depth, $\Delta x$ is the convection zone depth, $D_{a p p}$ is the apparent diffusion coefficient, $D_{R C M, O}$ is the chloride migration coefficient, $t$ is the life time and $t_{\text {real }}$ is the temperature of the water/air in contact with concrete.

\subsection{Probabilistic Approach}

Both models presented above allow for two different approaches, semi-probabilistic for LNEC E465 (2007), deterministic for fib Model Code (2010), and probabilistic for both cases. In the first two approaches each model's parameters are defined by their mean value, meaning that the model results have $50 \%$ chance of failure. However, in the semi-probabilistic approach a safety factor for lifetime, $\gamma$, is multiplied to the time parameter in order to increase it and thus to diminish the model's failure probability. The fib Model Code 2010 (2010) does not specify a way to reduce the failure probability, but by reducing its critical chloride concentration it is possible to do so. This was done in this paper by calculating the $5 \%$ percentile from the Beta distribution that describes the critical chloride concentration.

In the probabilistic approach the model's parameters are defined by their mean value and standard deviation. Using this approach, the first step is to define the limit state, which in this case is the depassivation of the reinforcement (expression 3), then applying the Monte Carlo simulation method on the model (with 1'000 samples) it is possible to calculate the limit state's failure probability.

$$
p=p_{\text {dep. }}=p\left\{C_{\text {crit. }}-C\left(a, t_{S L}\right)<0\right\}<p_{0}
$$

\section{Case Study}

The chosen structure as a case study in this paper is the oil tanker terminal and overlying viaduct in the Leixões harbour, located on Porto coastline, in Portugal (Pereira 2016). The present study focus on the structure's longitudinal beams, which are made of pre-stressed concrete, and have I cross section with a height of $1.10 \mathrm{~m}$ and $0.50 \mathrm{~m}$ width, fully connected to the steel tubes that support the structure. The overlying viaduct for automobile circulation is formed by three, and five in posts B and C, pre-stressed beams, with a height of $1.02 \mathrm{~m}$ linked by a $0.12 \mathrm{~m}$ thick slab, see Fig. 1. 


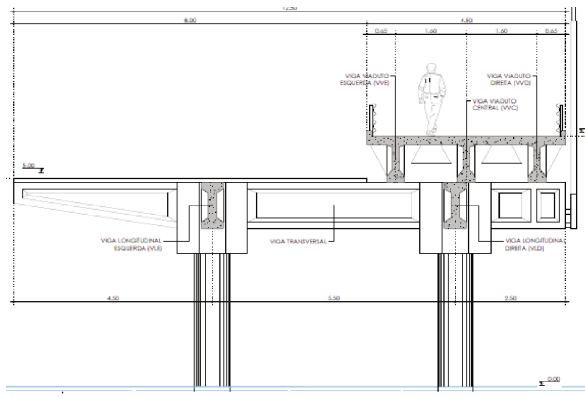

a)

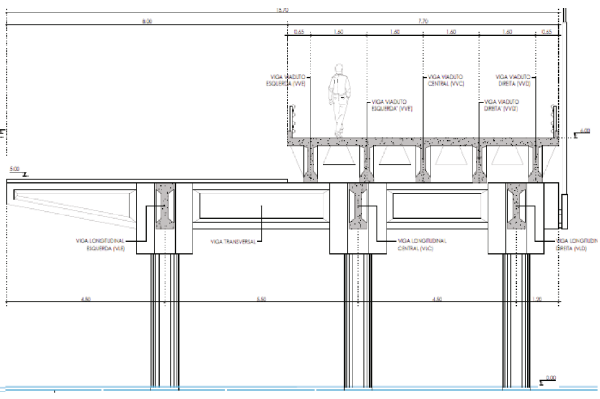

b)

Fig. 1. Cross-section: (a) General; (b) At posts B and C.

\subsection{Sensitivity Analysis}

In order to evaluate the influence of each model parameter and to reduce the computational cost of the probabilistic analysis, a sensitivity analysis was performed. Thus, for each parameter, an importance measure $b_{k}$, was obtained (Matos et al. 2016), see expression 4:

$$
b_{k}=\sum_{i=1}^{n}\left(\Delta y_{i, k} / y_{m, k}\right) /\left(\Delta x_{i, k} / x_{m, k}\right) \cdot C V
$$

where $b_{k}$ is the importance measure of parameter $k, \Delta y_{i, k}$ is the variation in structural response, $\Delta x_{i, k}$ is the variation of input parameter mean value $x_{m, k}, y_{m, k}$ is the average response, $n$ is the number of generated parameters and $\mathrm{CV}$ is the coefficient of variation of the assessed parameter.

Table 1 represents the parameters that were inputted in each model in order to obtain the importance measure, $b_{k}$ where the underlined parameters represent those obtained through in situ test result's taken from the structure, while the others represent the parameter's values taken from literature.

Table 1. Model parameters.

\begin{tabular}{l|l|l|l|l|l}
\hline \multicolumn{3}{l|}{ LNEC E465 (2007) } & \multicolumn{3}{l}{ fib Model Code $(2010)$} \\
\hline Parameters & Mean & St. Dev. & Parameters & Mean & St. Dev. \\
\hline$\underline{\mathrm{D}_{0}}\left(\mathrm{~m}^{2} / \mathrm{s}\right)$ & $2.39 \mathrm{E}^{-11}$ & $4.78 \mathrm{E}^{-12}$ & $\underline{\mathrm{D}_{\mathrm{RCM}, 0}}\left(\mathrm{~m}^{2} / \mathrm{s}\right)$ & $1.21 \mathrm{E}^{-11}$ & $2.42 \mathrm{E}^{-12}$ \\
\hline$\underline{\mathrm{C}_{\mathrm{s}}}(\% / \mathrm{wb})$ & 1.33 & 0.46 & $\underline{\mathrm{C}_{\mathrm{s}}}(\% / \mathrm{wb})$ & 1.33 & 0.46 \\
\hline$\underline{\mathrm{x}}(\mathrm{mm})$ & 47.35 & 4.55 & $\underline{\mathrm{C}_{\mathrm{nom}}}(\mathrm{mm})$ & 47.35 & 4.55 \\
\hline Temp $\left({ }^{\circ} \mathrm{C}\right)$ & 15 & 5 & $\mathrm{~T}_{\text {real }}(\mathrm{K})$ & 288 & 5 \\
\hline $\mathrm{n}(-)$ & 0.55 & 0.1 & $\mathrm{a}(-)$ & 0.3 & 0.12 \\
\hline & & $\mathrm{b}_{\mathrm{e}}(\mathrm{K})$ & 4800 & 700 \\
\cline { 3 - 6 } & & $\Delta \mathrm{x}(\mathrm{mm})$ & 10 & 5 \\
\hline
\end{tabular}


The results of the analysis for each model are given in Fig. 2, where there is also a limit value, $b_{\text {lim }}$, obtained from expert judgment, which separates the most critical parameters considered as random (above), from all the others that are adopted as deterministic (below), thus obtaining a lighter probabilistic model from a computational point of view.

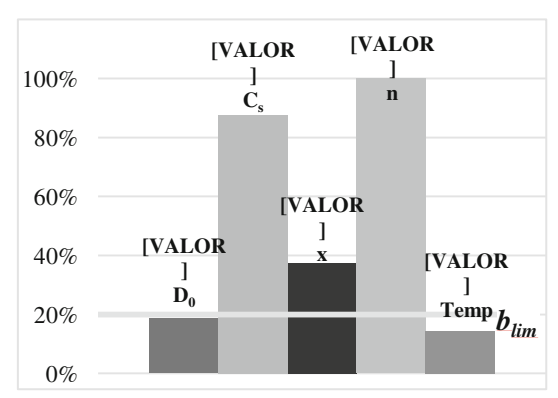

a)

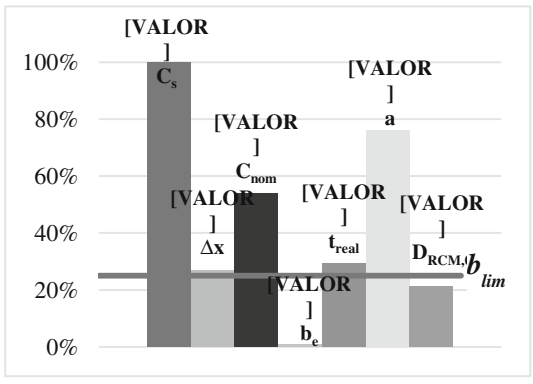

b)

Fig. 2. Importance measures (Pereira, 2016): (a) LNEC E465; (b) Model Code 2010.

\subsection{Deterioration Study}

Using the same data from the sensitivity analysis with the difference that the parameters $D_{O}$ and Temp for LNEC E465 (2007) and $D_{R C M, O}, b_{e}$, and $\Delta x$ for fib Model Code (2010) are forthwith considered as constant, it was possible to study the deterioration process during the initiation period and thus estimate when that period ended.

According to Fig. 3, by comparing the results of this analysis with the critical chloride content for each model (above) and with the target failure probability (below), the initiation period was estimated between 5 and 10 years and between 1 and 1, 5 years for the LNEC E465 (2007) semi-probabilistic and probabilistic approach, respectively, and between 15 and 20 years and between 9 and 9, 5 years for the deterministic and probabilistic approaches of the fib Model Code (2010), respectively. These results show that these models are too conservative to describe reality, and if this would be true then the structure would have ended its lifetime a long time ago. The main reason for this difference might be the abundance of cracks in the structure which are not taken into account by the models.

\subsection{Design Scenarios}

Using the LNEC E465 model, expression 5 was obtained where the maximum potential diffusion coefficient allowed is a function of concrete cover. Using a lifetime of 100 years which is the expected lifetime for a structure with the importance of the oil tanker terminal (RC3) and varying the concrete cover and type of cement, Fig. 4 was obtained where it is evident that the choice of an adequate type of cement is more important in terms of durability than reducing the W/B ratio, according to LNEC E465 (2007) model. 


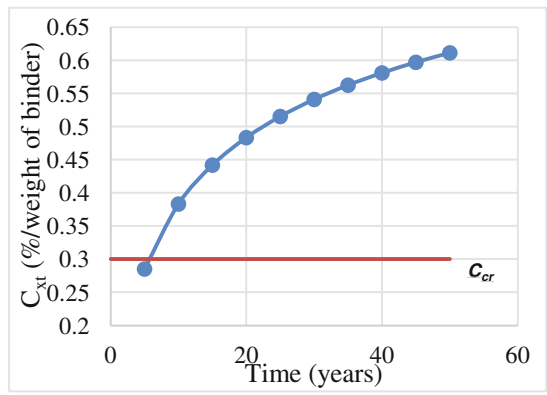

a)

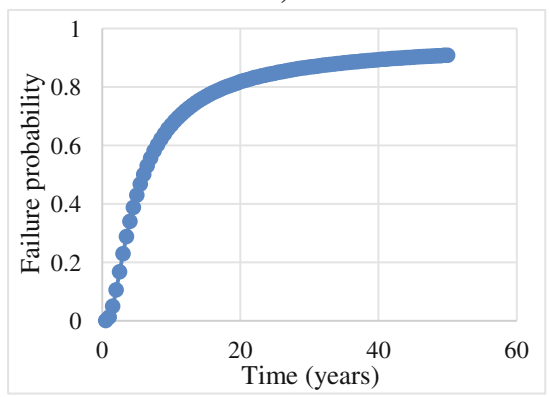

c)

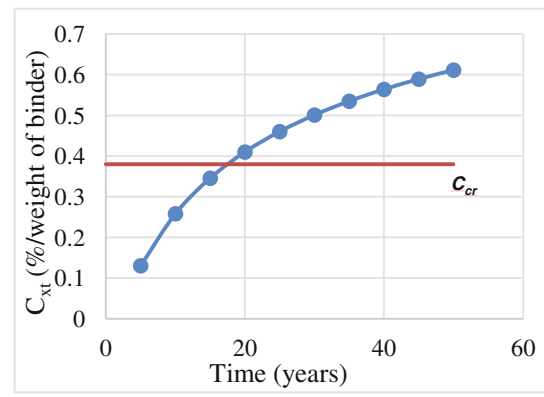

b)

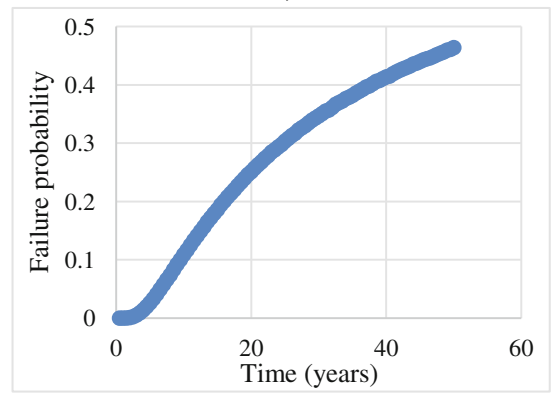

d)

Fig. 3. Computing the structure lifetime (Pereira 2016): (a) LNEC E465 Sem-Prob.; (b) Model Code Deter; (c) LNEC E465 Prob.; (d) Model Code Prob.

$$
\mathrm{D}_{0}=\frac{1}{\left(\frac{2}{x} e r f^{-1}\left(1-\frac{C_{r}}{C_{s}}\right)\right)^{2} \times t^{1-n} \times k \times t_{0}^{n}}
$$

Then, using the different approaches allowed by the two models, design concrete covers were also calculated in order to achieve 100 years' lifetime. The used cement types in this study were those specified in fib bulletin 34 (2006). In order to facilitate the comparison between models results, the $D_{R C M, O}$ values from fib Model Code (2010) were considered the same as the $D_{O}$ values from LNEC E465, just like the $C_{s}$ parameters which is only possible to calculate through the LNEC E465 (2007) model. Some parameters, however, assume the same values for every type of cement, for example the temperature is always $15^{\circ} \mathrm{C}$ with a standard deviation of $5^{\circ} \mathrm{C}, b_{e}$ is $4800 \mathrm{~K}$, and $\Delta x$ is $0 \mathrm{~m}$. The remaining input parameters in the models are presented in Table 2.

By introducing these values into the models, and by varying the concrete cover with a standard deviation of $1 \mathrm{~cm}$, it was possible to obtain the target failure probability for a lifetime of 100 years and thus to obtain the design concrete cover. In the non-probabilistic approach, the concrete cover was also varied for a lifetime of 100 years, thus obtaining the chloride profile for each type of concrete. Intercepting each binder's chloride profile with its own critical chloride content the design concrete covers were then obtained, see Table 3. 


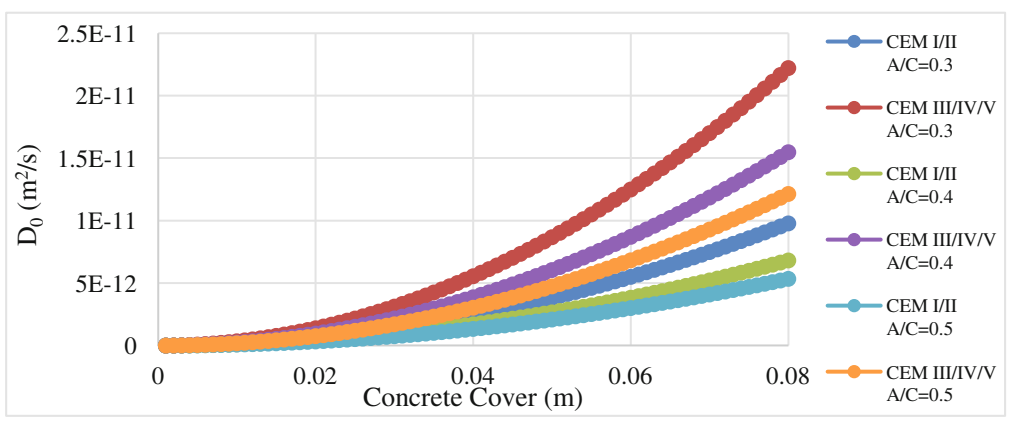

Fig. 4. LNEC E465 semi-probabilistic design scenarios (Pereira 2016).

Table 2. Input data (Pereira 2016).

\begin{tabular}{|c|c|c|c|c|c|c|c|c|c|}
\hline \multirow{2}{*}{\multicolumn{2}{|c|}{$\begin{array}{l}\text { Concrete type } \\
\mathrm{w} / \mathrm{b}\end{array}$}} & \multicolumn{2}{|l|}{ CEM I } & \multicolumn{2}{|c|}{ CEM I + CV } & \multicolumn{2}{|c|}{ CEM I + SF } & \multicolumn{2}{|c|}{ CEM III/B } \\
\hline & & 0.4 & 0.5 & 0.4 & 0.5 & 0.4 & 0.55 & 0.4 & 0.5 \\
\hline \multicolumn{10}{|c|}{ LNEC E465 } \\
\hline$D_{0}$ & Mean & $8.9 \mathrm{E}^{-12}$ & $15.8 \mathrm{E}^{-12}$ & $5.6 \mathrm{E}^{-12}$ & $9 \mathrm{E}^{-12}$ & $4.8 \mathrm{E}^{-12}$ & $5.3 \mathrm{E}^{-12}$ & $1.4 \mathrm{E}^{-12}$ & $2.8 \mathrm{E}^{-12}$ \\
\hline \multirow[t]{2}{*}{$C_{s}$} & Mean & 3.6 & 4.5 & 3.6 & 4.5 & 3.6 & 4.95 & 3.6 & 4.5 \\
\hline & StDev & 0.54 & 0.68 & 0.54 & 0.68 & 0.54 & 0.74 & 0.54 & 0.68 \\
\hline \multirow[t]{2}{*}{$n$} & Mean & 0.55 & 0.55 & 0.55 & 0.55 & 0.55 & 0.55 & 0.65 & 0.65 \\
\hline & StDev & 0.05 & 0.05 & 0.05 & 0.05 & 0.05 & 0.05 & 0.05 & 0.05 \\
\hline \multicolumn{10}{|c|}{ Model Code 2010} \\
\hline$D_{R C M, O}$ & Mean & $8.9 \mathrm{E}^{-12}$ & $15.8 \mathrm{E}^{-12}$ & $5.6 \mathrm{E}^{-12}$ & $9 \mathrm{E}^{-12}$ & $4.8 \mathrm{E}^{-12}$ & $5.3 \mathrm{E}^{-12}$ & $1.4 \mathrm{E}^{-12}$ & $2.8 \mathrm{E}^{-12}$ \\
\hline \multirow[t]{2}{*}{$C_{s}$} & Mean & 3.6 & 4.5 & 3.6 & 4.5 & 3.6 & 4.95 & 3.6 & 4.5 \\
\hline & StDev & 0.54 & 0.68 & 0.54 & 0.68 & 0.54 & 0.74 & 0.54 & 0.68 \\
\hline \multirow[t]{2}{*}{$a$} & Mean & 0.3 & 0.3 & 0.6 & 0.6 & 0.4 & 0.4 & 0.45 & 0.45 \\
\hline & StDev & 0.12 & 0.12 & 0.15 & 0.15 & 0.16 & 0.16 & 0.2 & 0.2 \\
\hline
\end{tabular}

Table 3. Design concrete cover (Pereira 2016).

\begin{tabular}{|c|c|c|c|c|c|c|c|c|c|}
\hline \multirow{2}{*}{\multicolumn{2}{|c|}{$\begin{array}{l}\text { Concrete type } \\
w / b\end{array}$}} & \multicolumn{2}{|c|}{ CEM I } & \multicolumn{2}{|c|}{$\begin{array}{l}\text { CEM } \\
\mathrm{I}+\mathrm{CV}\end{array}$} & \multicolumn{2}{|c|}{$\begin{array}{l}\text { CEM } \\
\mathrm{I}+\mathrm{SF}\end{array}$} & \multicolumn{2}{|c|}{$\begin{array}{l}\text { CEM } \\
\text { III/B }\end{array}$} \\
\hline & & 0.4 & 0.5 & 0.4 & 0.5 & 0.4 & 0.55 & 0.4 & 0.5 \\
\hline \multirow[t]{2}{*}{ LNEC E465 } & & 100 & 150 & 80 & 110 & 70 & 90 & 30 & 40 \\
\hline & & 111 & 165 & 91 & 127 & 85 & 102 & 43 & 58 \\
\hline \multirow[t]{2}{*}{ MC 2010} & & 120 & 170 & 40 & 50 & 60 & 70 & 30 & 40 \\
\hline & Prob & 175 & 252 & 60 & 80 & 110 & 129 & 62 & 93 \\
\hline
\end{tabular}




\section{Conclusions}

In this paper a deterioration study of a maritime structure considered at the end of its lifetime was conducted by applying two models that describe chloride diffusion on concrete structures. Analyzing the results of this study it is possible to compare the models and point out some weaknesses adjoined to their use in different scenarios. For example, either model demonstrated an initiation period which could be considered too conservative for the study of an existing structure. This gap is even higher if both cracking and the combined influence of carbonation in the structure is taken into account in the models. The design concrete cover study showed that many of the concretes studied are unpractical from an economic standpoint.

\section{References}

Ferreira, M.: Probability Based Durabulity Analysis of Concrete Structures in Marine Environment. Universidade do Minho (2004)

fib- Fédération Internationale du Béton. Model Code for Service Life Design. fib Belletin 34 (2006)

fib- Fédération Internationale du Béton. Model Code 2010 First complete draft, vol. 2. fib Bulletin 56 (2010)

LNEC- Laboratório Nacional de Engenharia Civil. Betões. Metodologia para estimar as propriedades de desempenho do betão que permite satisfazer a vida útil de projeto de estruturas de betão armado ou pré-esforçado sob as exposições ambientais XC e XS E-465. Lisboa, Portugal (2007)

Masters, L.W., Brandt, E.: Prediction of service life of building materials and components. Mater. Struct. 20(1), 55-77 (1987). doi:10.1007/BF02472728

Matos, J.C., Cruz, P.J.S., Valente, I.B., Neves, L.C., Moreira, V.N.: An innovative framework for probabilistic-based structural assessment with an application to existing reinforced concrete structures. Eng. Struct. 111, 552-564 (2016). doi:10.1016/j.engstruct.2015.12.040

Pereira, D.: Avaliação do Tempo de Vida Útil de Estruturas Marítimas - Aplicação à Ponte Cais do Porto de Leixões. University of Minho, Guimarães (2016) 